\title{
LA TRATA DE PERSONAS EN EL PERÚ, ANÁLISIS Y PERSPECTIVA
}

\author{
MARCO AURELIO TEJADA ORTIZ
}

\begin{abstract}
Resumen
El delito de "trata de personas" implica un comportamiento prohibido relacionado con el proceso de captación, transporte, traslado, acogida, recepción o retención de una persona, en el territorio de la República o de paso por el país, con fines de explotación $\mathrm{u}$ otro fines ilegales de este mismo carácter, pudiendo reputarse válidamente, a propósito, como una nueva forma de esclavitud, un delito transnacional y hasta un crimen de lesa humanidad al violentar con su perpetración Derechos Humanos consagrados, específicamente la libertad, la dignidad, la seguridad personal, el acceso a la justicia, el derecho a no ser sometido a la esclavitud, la servidumbre, los trabajos forzosos, el derecho a no ser sometido a torturas, el derecho a no ser objeto de violencia por motivos de género, la libertad de circulación, la salud física y mental, el derecho a condiciones de trabajo justas y favorables, el derecho a un nivel de vida adecuado, el derecho a la seguridad social y el derecho a no ser vendido ni ser objeto de comercio. Por esto resulta relevante la formación de una apreciación personal y funcional del glosado término punitivo "trata", no solo para así poder identificar, combatir, sancionar y erradicar esta creciente forma de "crimen organizado", sino, sobre todo, para seguir de cerca la evolución que viene alcanzando y que trasciende el ámbito nacional, que permiten clasificarlo como "crimen organizado transnacional".
\end{abstract}

Palabras clave: Trata, explotación sexual, explotación laboral, explotación en mendicidad.

\begin{abstract}
The crime of " human trafficking" involves a prohibited behavior related with the recruitment process, transport, transfer, reception or retention of a person in the territory of the country or passing through the country., for exploitation or other illegal purposes which can be regarded validly as a new form of slavery, a transnational crime and even a crime against humanity by violating its perpetration Enshrined human rights, specifically the freedom, the dignity, the personal security, access to the justice, the right in order not to be subjected to slavery, the servitude, the forced labor, the right not to be subjected to torture, the right not to be subjected to gender violence,
\end{abstract}

* Catedrático de Derecho Penal UIGV, juez penal titular de la Corte Superior de Justicia de la Libertad, juez penal provisional de la Sala Penal Nacional, maestro en Derecho Penal UNFV, asistente por Perú al curso: “Trata De Personas”, El Salvador. 
the freedom of circulation, the mental and physical health, the right to fair working and favorable conditions, the right to an adequate standard of living, the right to social security, and the right not to be sold or to be traded.

Because of this, it is relevant the formation of a personal and functional appreciation of the punitive term " trafficking" , in order not only to identify, combat, punish, and eradicate this growing form of " organized crime ", but especially in order to monitor the evolution that is achieving and that transcends the national scope and allowing to classify it as a " transnational organized crime".

Keywords: Trafficking, sexual exploitation, labor exploitation, begging exploitation.

\section{Sumario}

1.- Introducción. 2.- Legislación patria. 3.- Elementos. 4.- Modalidades. 4.1.- Explotación sexual. 4.2.- Explotación laboral. 4.3.- Explotación en mendicidad. 4.4.- Compra y venta de niños, niñas y adolescentes. 4.5.- Comercialización de órganos y tejidos. 4.6.Reclutamiento forzoso. 5.- Trata con agravantes. 6.- Política criminal. 7.- Bien jurídico protegido. 8.- Necesario distingo. 8.1.- Rufianismo. 8.2.- Proxenetismo. 8.3.Favorecimiento a la prostitución. 8.4.- Delito usuario - cliente. 8.5.- Delito de explotación sexual infantil y adolescente en ámbito del turismo. 8.6.- Delito de tráfico ilícito de migrantes. 9.- Consideraciones finales.

\section{Introducción}

$\mathrm{Al}$ interior de la ampulosa temática de carácter jurídico en el campo del "crimen organizado", coexiste a la fecha un asunto punible de acentuada connotación intitulado trata de personas que, en virtud de políticas definidas (D. S. 001-2015-JUS), el Estado Peruano busca combatir, frontal y decididamente $^{1}$, pues, en puridad, viene alcanzando niveles de incidencia ciertamente alarmantes que lo convierten - conjuntamente con los delitos de tráfico ilícito de drogas y tráfico ilícito de armas $^{2}$ - en una actividad punible sumamente lucrativa, marcadamente estigmatizante $y$, de facto, perniciosa para la estabilidad social, económica y jurídica de la Nación.

1 A. Controlando y reduciendo el fenómeno, mediante atención especial a los factores sociales y culturales que la generan con mejores conocimientos, y campañas de sensibilización.

B. Persiguiendo y sancionando eficientemente el delito, registrando y sistematizando las denuncias y procesos, y amparando a los testigos.

C. Atendiendo, protegiendo y recuperando integralmente a las víctimas, procurando entonces su reinserción y defensa judicial.

2 La Sala Penal Nacional, a guisa de ejemplo ejerce juditio - desde el año 2013 - en 59 casos por TID y en 6 casos por TIAF, lógicamente, de gran complejidad. 
La Organización de las Naciones Unidas calcula que el número aproximado de víctimas por año en "trata" a nivel mundial, asciende a cuatro millones $\left(4^{\prime} 000,000.00\right)$ de personas, de las cuales un millón trescientas mil $\left(1^{\prime} 300,000.00\right)$ personas, corresponden a América Latina y el Caribe. La Organización Internacional del Trabajo estima en doce millones trescientos mil $(12 ` 300,000.00)$ personas las víctimas de trabajo forzoso, de las cuales dos millones cuatrocientos mil $\left(2^{\prime} 400,000.00\right)$ personas son resultado de la "trata". Respecto a la "trata" con fines de explotación sexual, la Organización Internacional para las Migraciones aprecia que quinientas mil mujeres $(500,000.00)$, en promedio, claro está, ingresan a Europa cada año como víctimas de esta modalidad criminal. La misma Organización de las Naciones Unidas, advierte que el negocio de la "trata" mueve alrededor de nueve billones de dólares americanos $\left(99^{\prime \prime} 000,000.00\right)$ por año en el mundo3 . La oficina de las Naciones Unidas contra la Droga y el Delito, colige que la mayoría de las víctimas de "trata" detectadas son mujeres (entre el 55\% y el $60 \%$ ) y niñas (entre el $15 \%$ y el 20\%). Estimados recientes de la UNICEFF dan una cifra global de niños víctimas de la "trata" de más de un millón de personas $\left(1^{\prime} 000,000.00\right)$ al año.

De suyo, las personas traficantes, esto es, los individuos activos que hacen del delito de "trata de personas" su modo de vida y que, de hecho, aprovechan casi siempre situaciones de pobreza y de pobreza extrema ${ }^{4}$, persuaden por lo general a sus potenciales víctimas mintiendo groseramente sobre la actividad que éstas - los sacrificados - desempeñaran en el lugar de destino, diciéndoles por ejemplo que trabajarán de niñeras, enfermeras, camareras, cocineras, anfitrionas, etc.; no obstante, los fines de la explotación no serán develados sino hasta después de la llegada de la víctima a la anhelada estancia 5 . Otras veces, estos mismos traficantes, igualmente,

3 La Oficina de las Naciones Unidas para el Control de Drogas y la Prevención del Crimen reconoce a la trata de personas como la conducta delictiva de más rápido crecimiento en el crimen organizado.

4 La pobreza y la falta de oportunidades en el lugar de origen hacen que la potencial víctima acepte ofertas dudosas de personas desconocidas, o que se vea traicionada por personas conocidas, incluso seres amados que ven en ella una oportunidad de mejora. Sin embargo, la pobreza no es la única causa o causa "per se" de la trata, pero si una facilitadora en la que la trata se desenvuelve. La pobreza favorece la vulnerabilidad que los explotadores aprovechan para captar a sus víctimas más fáciles. (Trata de mujeres para fines sexuales comerciales en el Perú; Oficina Regional para los Países Andinos, Organización Internacional para las Migraciones., p. 22.http:/.www.oimlima.org.pe.)

5 Las víctimas suelen ser objeto de trata mediante la captación y el traslado de un país a otro o dentro de un mismo país, generalmente desde determinadas áreas rurales hacia centros 
cautivan a sus ocasionales mártires siendo esta vez abiertos sobre la actividad laboral planificada, pero no sobre las condiciones en las que dicha actuación se llevará ciertamente a cabo; así, nunca les dirán a los casuales sacrificados, igualmente a guisa de ejemplo, que trabajarán continuamente, durante muchas horas, por encima de la jornada ordinaria de trabajo, en condiciones altamente peligrosas, con limitación incluso de su libertad ambulatoria, o que no recibirán puntual y totalmente el pago que se les prometió al inicio y que fuera, en esencia, claro está, el factor que permitió al tratado optar por aceptar la propuesta formulada.

Los tratantes, en todo caso, al asegurar sus ganancias en virtud a la llamada explotación coactiva o fuerte, es decir, la relación de subordinación entre la víctima y el explotador, quien no se beneficia con la simple actividad de la víctima, sino con la victima propiamente dicha, degradándola prácticamente a la condición de objeto, mercancía o cosa, lo hacen generalmente en el marco estricto de actividades de suyo prohibidas como son la venta de niños, niñas o adolescentes, la prostitución y cualquier forma de explotación sexual, la esclavitud o prácticas análogas a la esclavitud, cualquier forma de explotación laboral, la mendicidad, los trabajos o servicios forzados, la servidumbre, la extracción o tráfico de órganos o tejidos somáticos o sus componentes humanos, así como cualquier otra forma análoga de explotación 6 .

La expresión punible "trata de personas" incluye, para determinados estudiosos de la materia, la efectiva explotación (sexual, laboral o doméstica) de las víctimas, mientras que para otros especialistas esta última situación es solo el objeto o finalidad del negocio; naturalmente, el mismo concepto de explotación (sexual, laboral o doméstica) puede tener diversos alcances interpretativos, dependiendo claro está de la perspectiva en que fuere empleada.

Al punto, dos de los más importantes obstáculos con el cual acostumbramos a enfrentarnos en la vida práctica los operadores del sistema y sobre todo los aplicadores de la justicia punible, sin distingo de latitud, es la complicada comprensión del tipo penal y asimismo del bien jurídico protegido en el delito de "trata de personas"; se invocan y requieren, pues, explicaciones claras y macizas al respecto. El derecho comparado, favorablemente, nos

urbanos igualmente advertidos (Informe de Investigación 62/2014-2015 del Congreso de la República del Perú: http://www.congreso.gob.pe/dgp/didp/inicio.htm)

6 Código Penal. Art. $153^{\circ}$, modificado por ley 30251. 
provee de muy buenas armas para dicha afrontar dicha coyuntura7 .

Consideramos que resulta relevante la formación de una apreciación personal y funcional del glosado término "trata de personas", no solo para así poder identificar, combatir, sancionar y erradicar con denuedo esta cada vez más creciente forma de crimen organizado, vale decir, agrupación de tres o más personas que se reparten diversas tareas o funciones, cualquiera sea su estructura y ámbito de acción, que, con carácter estable o tiempo indefinido se crea, existe o funciona inequívoca y directamente, de manera concertada y coordinada, con la finalidad de cometer uno o más delitos graves (Art. $2^{\circ}$ de la ley 30077 , ley contra el crimen organizado) ${ }^{8}$, sino, sobre todo, para seguir de cerca la evolución que viene alcanzando y que en línea de reacción trasciende resbaladizamente el ámbito nacional - con características propias - que permiten clasificarlo sin duda como "crimen organizado transnacional"9.

Ahora bien, en el contexto ecuménico advertido y como queda expresado, debemos reiterar en principio que el delito de "trata de personas" es, en efecto, una sustanciosa fuente de ganancias para las organizaciones criminales destinadas a cometer delitos diversos como el narcotráfico y el tráfico de armas; no obstante, a diferencia del tráfico de armas y del delito de tráfico de drogas, el "comercio de personas" con fines de explotación (sexual, laboral o doméstico) no tiene costo, debido al debilitado combate institucional existente - incipiente ${ }^{10}$ - aún en nuestro país.

7 En razón de que la "trata" vulnera bienes jurídicos como la libertad, la integridad y la vida entre otros - los convenios sobre este rubro son reputados "Tratados de Derechos Humanos"; en ese sentido, el acotado Protocolo de Palermo contiene normas de carácter auto-aplicativo que, por lo mismo, deben aplicarse ipso facto por el operador judicial (Art. $3^{\circ}$ inc. B, que considera irrelevante el "consentimiento" para la configuración del suceso).

8 Participación de dos o más personas para el acometimiento de un propósito único y garantizar su continuidad para desarrollar una o más actividades de carácter delictivo (Vilma Guadalupe Portillo; la explotación sexual comercial como crimen organizado y su dimensión transnacional. Apuntes para la aplicación de la legislación sobre explotación sexual comercial de personas menores de edad. Boletín temático $\mathrm{N}^{\circ}$ 5., p. 2).

9 Nivel organizativo que se apropia de la tecnología y cuenta con recursos adecuados para su funcionamiento, un objetivo primordial que es la rentabilidad - obtención de las mayores ganancias económicas posibles - la división de trabajo, el reparto de roles y la especialización de la mano de obra y de las jerarquías (Vilma GUADALUPE PORTILLO. Obra cito., p. 2).

10 El subrayado es nuestro. 


\section{Legislación patria}

En el Perú, el delito de "trata de personas" al inicio de su regulación se hallaba previsto y sancionado ${ }^{11}$ como ilícito penal contra la libertad en el contexto del llamado delito de proxenetismo; en efecto, el artículo $182^{\circ}$ del Código Penal del año 1991 lo contenía con el siguiente enunciado: "el que promueve o facilita la entrada o salida del país o el traslado dentro del territorio de la república de una persona para que ejerza la prostitución", razón por la cual sus elementos configurativos de carácter objetivo eran:

a) La promoción o facilitación, para la entrada o salida del país o para el traslado dentro del territorio de la república, y

b) Una persona empleada en el ejercicio de la prostitución.

Posteriormente, el día 08 de junio del año 2004, en virtud de la norma contenida en el artículo $1^{\circ}$ de la ley 28251 , el mentado numeral $182^{\circ}$ del Código Penal - siempre como parte del modo sexual: proxenetismo - fue objeto de modificación legislativa tanto en su contenido como igualmente en su penalidad ${ }^{12}$, con el siguiente epígrafe: "el que promueve o facilita la captación para la salida o entrada del país o el traslado dentro del territorio de la República de una persona para que ejerza la prostitución, someterla a esclavitud sexual, pornografía u otras formas de explotación sexual", deviniendo entonces en elementos configuradores de orden objetivo, los siguientes:

a) La promoción o facilitación de la captación para la salida o entrada del país o el traslado dentro del territorio de la república, y.

b) Una persona destinada al ejercicio de la prostitución, a la esclavitud sexual, a la pornografía u a otras formas de explotación sexual.

Más adelante, en virtud de la 5ta. disposición complementaria, transitoria y final de la Ley $28950^{13}$, el señalado artículo $182^{\circ}$ del instrumento represor del año 1991 fue explícitamente suprimido ${ }^{14}$, decidiéndose en aquel instante redefinir el comportamiento prohibido de la "trata de personas"15 en el

11 Con pena privativa no menor de cinco ni mayor de diez años para la modalidad simple y pena no menor de ocho ni mayor de doce años por concurrencia de circunstancias agravantes (리 agente es el padre, la madre, el tutor o el curador).

12 Con pena privativa de libertad no menor de cinco ni mayor de diez años para la modalidad simple y pena privativa de libertad no menor de diez ni mayor de doce años, si media alguna de las circunstancias agravantes enumeradas en el artículo anterior.

13 Publicada el 16 de enero del año 2007.

14 Derogado.

15 Por razones de política criminal, se dijo entonces. 
artículo $153^{\circ}$ del Código Penal ${ }^{16}$ que precedentemente hacía alusión al tráfico, retención o traslado de menores de edad o personas incapaces de valerse por sí mismas, como delito contra la libertad, pero en la modalidad ya de atentado pernicioso al bien jurídico protegido libertad personal, con el siguiente enunciado: "el que promueve, favorece, financia o facilita la captación, transporte, traslado, acogida, recepción o retención de otro, en el territorio de la República o para su salida o entrada del país, recurriendo a: la violencia, la amenaza u otras formas de coacción, la privación de libertad, el fraude, el engaño, el abuso del poder o de una situación de vulnerabilidad, o la concesión o recepción de pagos o beneficios, con fines de explotación, venta de niños, para que ejerza la prostitución, someterlo a esclavitud sexual u otras formas de explotación sexual, obligarlo a mendigar, a realizar trabajos o servicios forzados, a la servidumbre, la esclavitud o prácticas análogas a la esclavitud u otras formas de explotación laboral, o extracción o tráfico de órganos o tejidos humanos".

En este sentido, los elementos de configuración objetiva del tipo penal "trata de personas", en ese momento, eran:

a) La promoción, el favorecimiento, el financiamiento o la facilitación de la captación, transporte, traslado, acogida, recepción o retención de otro, en el territorio de la república o para su salida o entrada del país.

b) La violencia, amenaza, coacción, privación de libertad, fraude, engaño, abuso del poder o de una situación de vulnerabilidad, concesión o recepción de pagos o beneficios.

c) La explotación: venta de niños, ejercicio de la prostitución, sometimiento a esclavitud sexual $\mathrm{u}$ otras formas de explotación sexual, mendicidad, trabajos o servicios forzados, servidumbre, esclavitud o prácticas análogas u otras formas de explotación laboral, extracción o tráfico de órganos o tejidos humanos.

A partir de dicho instante cronológico, en concreto, queda establecido legalmente en nuestro país, pues, qué la captación, transporte, traslado, acogida o recepción de un niño, niña o adolescente con fines de explotación, es "trata", aún cuando no se hubiera recurrido a alguno de los medios de comisión señalados expresamente en la ley sustantiva de la materia.

16 Reprimiéndolo con pena privativa no menor de ocho ni mayor de quince años. 
En el ínterin, sin embargo y debido al constante cambio de paradigmas, criterios, circunstancias y partícipes advertidos de plano en el delito de "trata", fundamentalmente en el contexto internacional, mediante artículo único de la Ley $30251^{17}$, el numeral $153^{\circ}$ del Código Penal es nuevamente objeto de cambios, señalándose: "el que mediante violencia, amenaza u otras formas de coacción, privación de la libertad, fraude, engaño, abuso de poder o de una situación de vulnerabilidad, concesión o recepción de pagos o de cualquier beneficio, capta, transporta, traslada, acoge, recibe o retiene a otro, en el territorio de la República o para su salida o entrada del país con fines de explotación, será sancionado con pena privativa de libertad no menor de ocho ni mayor de quince años.

Razón por la cual los elementos objetivos y configuradores del tipo penal "trata de personas" son:

a) La conducta: captar, transportar, trasladar, acoger, recibir o retener a otro en el territorio de la república o para su salida o entrada del país.

b) El medio: violencia, amenaza, coacción, privación de la libertad, fraude, engaño, abuso de poder o de una situación de vulnerabilidad, concesión o recepción de pagos o de cualquier beneficio.

c) El fin: explotación: venta de niños, niñas o adolescentes, prostitución y cualquier forma de explotación sexual, esclavitud o prácticas análogas, cualquier forma de explotación laboral, mendicidad, trabajos o servicios forzados, servidumbre, extracción o tráfico de órganos o tejidos somáticos o sus componentes humanos, así como cualquier otra forma análoga de explotación.

De todo esto se desprende, a la sazón, que la captación, transporte, traslado, acogida, recepción o retención de un niño, de una niña o de un (a) adolescente con fines de explotación es "trata" incluso cuando no se recurriera a alguno de los medios previstos en el inciso 1. De igual modo, deviene en prístino que el consentimiento otorgado por la víctima mayor de edad a cualquier forma de explotación, carecerá de efectos jurídicos cuando el agente activo hubiere recurrido a cualquiera de los medios comisivos enunciados en el citado inciso 1.

17 Publicada el día 21 de octubre del año 2014. 
En esta línea de reflexión y análisis, en consideración de la normativa internacional, debidamente suscrita y ratificada por el Estado Peruano ${ }^{18}$, podemos afirmar que el hecho punible en la modalidad de "trata de personas" (artículo $153^{\circ}$ del Código Penal, modificado por la ley $30251^{19}$ ), importa en la praxis, por tanto, un comportamiento indebido relacionado con el proceso de captación, transporte, traslado, acogida, recepción o retención de una persona, en el territorio de la república o de paso por el país, con fines de explotación $\mathrm{u}$ otro fines ilegales, pudiendo reputarse entonces como una nueva forma de esclavitud, un delito transnacional y por qué no decirlo un crimen de lesa humanidad debido a que violenta flagrantemente derechos humanos consagrados en nuestra sistemática jurídica patria y asimismo en la jurisdicción internacional, específicamente la libertad, la dignidad, la seguridad personal, el acceso a la justicia, el derecho a no ser sometido a la esclavitud, la servidumbre, los trabajos forzosos, el derecho a no ser sometido a torturas, el derecho a no ser objeto de violencia por motivos de género, la libertad de circulación, la salud física y mental, el derecho a condiciones de trabajo justas y favorables, el derecho a un nivel de vida adecuado, el derecho a la seguridad social y el derecho a no ser vendido ni ser objeto de comercio.

Como puede inferirse de las anotaciones precedentes, por consiguiente, la definición del delito de "trata de personas" resulta de suya altamente compleja debido a la inclusión en su contexto de conductas que podrían, inclusive, considerarse delitos independientes en nuestro ordenamiento jurídico.

Entonces, el mentado artículo $153^{\circ}$ de nuestro actual Código Penal (modificado por Ley $\mathrm{N}^{\circ} 30251$ ), al definir esta forma de criminalidad organizada, hace expresa alusión a la persona que promueve, favorece, financia o facilita la captación, el transporte, el traslado, la acogida, la recepción o la retención de otro, en el territorio de la república o para su salida o entrada del país, recurriendo a la violencia, la amenaza u otras formas de coacción, la privación de libertad, el fraude, el engaño, el abuso del poder o de una situación de vulnerabilidad, o la concesión o recepción de pagos o beneficios, con fines de explotación, venta de niños, para que ejerza la prostitución, someterlo a esclavitud sexual u otras formas de explotación sexual, obligarlo a mendigar, a realizar trabajos o servicios forzados, a la

18 Convención de las Naciones Unidas contra la Delincuencia Organizada Transnacional (Protocolo de Palermo, diciembre 2000).

19 Publicada el 21 de octubre del año 2014. 
servidumbre, la esclavitud o prácticas análogas a la esclavitud u otras formas de explotación laboral, o extracción o tráfico de órganos o tejidos humanos ${ }^{20}$.

\section{Elementos}

En expresa conformidad con lo establecido en el artículo $3^{\circ}$ de la Convención de las Naciones Unidas contra la Delincuencia Organizada Transnacional y el informe de investigación 62/2014-2015 del Congreso de la República21, podemos advertir, precisar y relievar los tres (03) elementos básicos y constitutivos del delito de "trata de personas"; a saber:

a) El acto o conducta impetrada (léase: lo que se hace).

b) Los medios comisivos empleados (léase: cómo se hace).

c) La finalidad perseguida por el actor (léase: por qué se hace).

\section{a. La conducta}

Es la circunstancia referida al menos a una de las seis etapas del proceso de "trata" (captación, transporte, traslado, acogida, recepción o retención de víctimas).

Este elemento de configuración, ergo, se encuentra especialmente relacionado con el desplazamiento y con la migración; en efecto, como sabemos, la víctima de la "trata" es desplazada casi siempre desde su lugar de origen hasta otro lugar que normalmente no conoce y en el cual espera cree encontrará - un mayor bienestar.

Es importante enfatizar al respecto, no obstante, que las numerosas víctimas de este tipo penal de esclavitud ecuménica no siempre son raptadas, forzadas o violentadas, esto es, obligadas contra su expresa y común voluntad e intención de emerger en la vida de relación; muchas de ellas quizás la gran mayoría - se traslada (viaja) voluntariamente y con predispuesta disposición, creyendo entonces en falsas promesas de empleo, estudios y/o proyectos de vida, de suyo seductoras.

\section{b. Los medios}

Son aquellos elementos que privan la libertad o vician cuando menos el consentimiento de la víctima (violencia, amenaza, coacción, privación de la

20 Sancionándolo con pena privativa de libertad no menor de ocho ni mayor de quince años.

21 Área de servicios de investigación., p. 12. http://www.congreso.gob.pe/dgp/didp/inicio.htm 
libertad, fraude, engaño, abuso de poder o de una situación de vulnerabilidad, concesión o recepción de pagos o de cualquier beneficio).

A propósito, si bien es verdad las numerosas víctimas son las más de las veces privadas de su libertad ambulatoria y maltratadas físicamente en la captación, traslado y retención, la violencia psicológica, moral o amenaza se convierte en la forma más recurrente de esta forma de agresión inhumana.

Luego, de estos mecanismos de control identificados en doctrina y en la jurisprudencia nacional y extranjera, los más empleados en el negocio de la "trata" son:

i. Las deudas, representadas por los tratantes en gastos de traslado, tramitación de documentación falsa, alojamiento, alimentación, etc.

ii. La retención de documentos, que es una de las primeras decisiones que asumen los tratantes en perjuicio de sus víctimas, las cuales por lo mismo tienen firme dificultad para movilizarse y evitar de ese modo la deportación y/o su descubrimiento.

iii. Las adicciones, que son recursos vedados empleados por los tratantes, induciendo a los tratados en el consumo de drogas.

iv. La seducción, que son procedimientos ilegítimos de los cuales se valen los tratantes en desmedro, especialmente, de niños, niñas y mujeres.

v. La manipulación de la información, que previamente han obtenido los tratantes de sus víctimas y que, de facto, les permiten mantener en estado de alerta no solamente a dichos agraviados sino igualmente a las personas del entorno de éstas.

\section{c. Los fines}

La explotación es el objetivo final de la "trata"; a propósito, no existe en la vida de relación un solo caso de "trata de personas" que no conlleve ciertamente a la explotación. Naturalmente, la "trata de personas" que se realiza siempre con algún propósito de explotación, debe ser objeto de sanción, incluso, aún cuando dicha intención realmente no fuere alcanzada en la realidad específica ${ }^{22}$.

22 La finalidad del tratante no debe, necesariamente, concretarse, basta con que se haya realizado alguna de las conductas y que se pueda comprobar la pretendida finalidad. La Trata de Personas en el Perú; normas, casos y definiciones., p. 31. Capital Humano y Social Alternativo; www.chs-perú.com 
Venta de niños o adolescentes, prostitución, explotación sexual, esclavitud, explotación laboral, mendicidad, trabajos forzados, servidumbre, extracción o tráfico de órganos o tejidos somáticos o sus componentes humanos.

\section{Modalidades}

En lo concerniente a las maneras que el hecho punible "trata de personas" ostenta en la praxis, de mano con la doctrina más pacífica podemos relievar las siguientes connotaciones; a saber:

4.1 Explotación sexual: es la forma más asociada a la "trata".

- Aprovechamiento de la prostitución ajena.

La víctima es inducida, obligada o forzada a ejercer el comercio del sexo contra su voluntad y en beneficio lógicamente del tratante.

- Pornografía.

La víctima es coaccionada a desempeñar esta forma industrial de comercio sexual.

- Explotación sexual en el ámbito del turismo.

El mercado sexual es un móvil turístico muy trascendente.

4.2 Explotación laboral: aprovechamiento del trabajo de uno en beneficio de otro.

La trata laboral transcurre normalmente en el contexto mismo de la economía informal.

- En agricultura: Cosechas de caña de azúcar, recojo de castañas u otras labores concernientes.

- En la tala: Venta de madera en el mercado informal.

- En minería: Minería artesanal.

- En las fábricas: Trabajar sin descanso, sin alimento, sin remuneración.

- En el trabajo doméstico: Extrema vulnerabilidad de las víctimas. 
4.3 Explotación en mendicidad, especialmente por efectos de la pobreza.

Práctica consistente en solicitar dádivas o limosnas, en donde las víctimas son generalmente niños, niñas, adolescentes, ancianos y personas con discapacidad.

\subsection{Compra y venta de niños, niñas y adolescentes.}

Normalmente redes internacionales están detrás de esta modalidad delictuosa. Las víctimas son sustraídas, secuestradas o alejadas de sus familias, por lo general a cambio de ingentes sumas de dinero.

\subsection{Comercialización de órganos y tejidos}

Es la forma más cruenta del delito de trata que poco a poco viene ganando grandes espacios de punibilidad.

\subsection{Reclutamiento forzoso}

Tiene lugar en situaciones de violencia interna por parte de grupos armados regulares o irregulares que procuran cuadros de adherentes con fines de combate, vigilancia, guías, espionaje, limpieza y transporte de armas.

\section{Trata con agravantes}

Conforme a la normativa inserta en el artículo $153^{\circ}$-A del señalado Código Penal Peruano del año 1991 -modificado por el Artículo $1^{\circ}$ de la Ley 28950-el hecho punible en forma de "trata de personas" se hace más pernicioso, en una doble escala de punición más alta; a saber:

\section{a) Cuando:}

i. $\quad$ El agente comete el hecho abusando del ejercicio de la función pública.

ii. El agente es promotor, integrante o representante de una organización social, tutelar o empresarial, que aprovecha de esta condición para perpetrar este delito.

iii. Existe pluralidad de víctimas.

iv. La víctima frisa entre catorce y dieciocho años de edad o es incapaz. 
v. El agente es cónyuge, conviviente, adoptante, tutor, curador, pariente hasta el cuarto grado de consanguinidad o segundo de afinidad, o tiene a la víctima a su cuidado por cualquier motivo o habitan en el mismo hogar.

vi. El hecho es cometido por dos o más personas ${ }^{23}$.

\section{b) Cuando:}

i. Se produce la muerte, lesión grave o se pone en inminente peligro la vida y la seguridad de la víctima.

ii. La víctima es menor de catorce años de edad o padece, temporal o permanentemente, de alguna discapacidad física o mental.

iii. El agente es parte de una organización criminal24 .

\section{Política criminal}

En nuestro país, colateralmente, a pesar de que el Ministerio Público ha implementado a la fecha órganos de persecución especializadas en "trata", no existen ni se elaboran a entera satisfacción auténticas acciones de prevención de oficio respecto de esta modalidad criminal organizada, no obstante, la notoria existencia de publicaciones y avisos de falsas agencias de empleo, guías de turismo, servicios de masajes, modelajes, casting para actuación en televisión o novelas, etc. De hecho, resulta imprecisa - por decir lo menos - la investigación de naturaleza proactiva, siendo esto así, seguramente, de una parte, por la muy elevada carga procesal o laboral que soportan los mentados despachos Fiscales Provinciales Penales y la Policía Nacional del Perú en los llamados casos criminales de carácter común y, de otro lado, por falta de sensibilización y/o motivación de la propia colectividad o, según el caso, de las mismas víctimas renuentes a cooperar en el debido y necesario esclarecimiento del suceso.

La investigación policial y fiscal en esta clase de ilicitudes penales, efectivamente, tiene casi siempre naturaleza reactiva iniciándose de suyo debido a la formulación de la denuncia presentada por la víctima, o por sus familiares o, eventualmente, por terceros interesados.

23 Sancionándolo con pena no menor de doce ni mayor de veinte años de privación de libertad e inhabilitación conforme al artículo 36 incisos 1, 2, 3, 4 y 5 del Código Penal.

24 Imponiéndole pena privativa de libertad no menor de 25 años. 
En todo caso, no se ha diseñado aún en el Perú una adecuada estrategia de investigación, pues, las diligencias de estilo se limitan por lo general a la mera declaración de la parte denunciante, a la recepción del testimonio del individuo denunciado y a la diligencia de reconocimiento médico-legal de la presunta víctima, que de no concretarse conllevan siempre a un archivo definitivo de las pesquisas preliminares sin mayor análisis, cuando fácilmente podrían buscarse las evidencias del delito de "trata" a través del manejo inteligente de la información recibida como noticia criminal y de acciones coordinadas de inteligencia entre el Ministerio Público, la Policía Nacional y la misma colectividad en su conjunto.

\section{Bien jurídico protegido}

En cuanto al bien jurídico protegido en el delito de "trata de personas", no obstante la diversidad de criterios existentes y el hecho de que en esta ilicitud penal, sin duda, no concurre un único bien jurídico al cual la ley penal protege o procura proteger a entera satisfacción, sino más bien una pluralidad de dichos atributos legales (libertad ambulatoria, libertad sexual, indemnidad sexual, salud física y mental, libertad de auto determinación, seguridad laboral) $)^{25}$, conforme a la normativa inserta en el artículo $1^{\circ}$ de la Constitución Política del Estado del año 199326, nos adherimos al sector de la doctrina especializada que establece como objeto de protección la "dignidad humana", entendida esta como el derecho de todos los habitantes del planeta (mayores o menores de edad) a no ser instrumentalizados por otro, es decir, a no ser tratados ni considerados como meros objetos de cambio o mercancía.

Justamente, teniendo en expresa cuenta, mutatis mutandi, que a partir de la Declaración Universal de los Derechos Humanos ${ }^{27}$ la dignidad humana es inviolable debiendo por tanto ser respetada y protegida ${ }^{28}$, en el delito de

25 En el delito de trata de personas el bien jurídico protegido es la libertad personal en su variante de la autodeterminación; es decir, el Estado en este delito protege la libertad, el libre albedrío, la voluntad, el libre arbitrio de la persona de decidir sobre su proyecto de vida, su libre decisión, y garantizar la autonomía con que debe desempeñarse todo ser humano. (Thonn Medina Olivas, el bien jurídico en la trata de personas - Perú. Monografias.com > Derecho. http://www.monografias.com/trabajos93/bien-juridico-trata-personas-peru/bien-juridicotrata-personas peru.shtml\#ixzz43YLQKsiE)

26 Artículo 1.- La defensa de la persona humana y el respeto de su dignidad son el fin supremo de la sociedad y del Estado.

2710 de diciembre del año 2008

28 Artículo 1. Todos los seres humanos nacen libres e iguales en dignidad y derechos $\mathrm{y}$, dotados como están de razón y conciencia, deben comportarse fraternalmente los unos con los otros. 
"trata de personas" -conforme reseña Ana Isabel Pérez Cepeda29- y conforme lo venimos asimismo esbozando, nos hallamos en presencia de una lacerante conversión del ser humano en un mero objeto, en un individuo absolutamente cosificado, en una mercancía sujeta por entero a la sola voluntad de otro, en un mero instrumento asible, mensurable, manipulable, inventariable y cuantificable.

Sobre esto, parafraseando a Medina Olivas ${ }^{30}$ podemos advertir que "el privilegio de la valoración del bien jurídico protegido es un arma de doble filo que -a veces ${ }^{31}$ - se presta para que algunos jueces al valorar los hechos, así como el abogado de la defensa, se valgan de la existencia del consentimiento de la víctima, con lo que, se termina excluyendo de responsabilidad penal a los imputados o procesados, sobre todo cuando se trata de víctimas mayores de edad, sin tener en consideración lo señalado en el literal b) del artículo $3^{\circ}$ del Protocolo para prevenir, reprimir y sancionar la trata de personas, que complementa la Convención de las Naciones Unidas contra la Delincuencia Organizada Transnacional, la cual advierte que el consentimiento dado por la víctima de la "trata" a toda forma de explotación intencional descrita en el apartado a) del presente artículo no se tendrá en cuenta cuando se hubiere recurrido a cualquiera de los medios enunciados en dicho apartado".

En lo demás, debemos afirmar que nuestro país, a la fecha, es considerado en el contexto internacional como lugar de origen, tránsito y destino para el delito de "trata de personas", básicamente, en tres de los fines de explotación precedentemente glosados: sexual, laboral y doméstico, siendo las zonas de mayor incidencia detectadas las ciudades de Lima, Cuzco, Iquitos, Arequipa, Puno y Piura. Lógicamente, las estadísticas reflejan una cruda realidad: la mayor incidencia de casos de "trata" se materializa en la explotación sexual de mujeres y menores de edad.

\section{Necesario distingo}

A manera de colofón si se quiere, nos permitiremos formular un objetivo y muy breve distingo entre el delito de "trata de personas" que, como afirmamos, importa en sentido práctico la perniciosa mutación del hombre a

$(\ldots)$

Artículo 4. Nadie estará sometido a esclavitud ni a servidumbre, la esclavitud y la trata de esclavos están prohibidas en todas sus formas.

29 Las Normas Penales Españolas: Cuestiones Generales. Trata de Personas y Explotación Sexual. Editorial COMARES. 2006., p.173.

30 Obracito.

31 El subrayado es nuestro. 
un mero objeto, en un individuo cosificado, a una mercancía sujeta por entero a la sola voluntad de otro, y los demás ilícitos de carácter penal considerados afines como es el caso, del rufianismo ${ }^{32}$, del proxenetismo ${ }^{33}$, del favorecimiento a la prostitución ${ }^{34}$, del delito usuario cliente ${ }^{35}$, del delito de explotación sexual infantil y adolescente en ámbito del turismo ${ }^{36} \mathrm{y}$ del delito de tráfico ilícito de migrantes ${ }^{37}$.

\subsection{Rufianismo}

Delito en el cual, los sujetos activos se hacen mantener total o parcialmente por otra persona que hace del ejercicio de la prostitución su modo de vida. “...el Rufián... no promueve ni obliga de ninguna manera a la víctima a ejercer la prostitución...solo se aprovecha de las ganancias que el sujeto pasivo obtiene del ejercicio de la prostitución... en la que aquél para nada interviene, actividad que la víctima puede haber elegido libre y voluntariamente"...38.

32 Artículo 180.- Rufianismo, modificado por el artículo $1^{\circ}$ de la Ley 28251:08-06-2004

Explotar la ganancia obtenida por una persona que ejerce la prostitución

33 Artículo 181.- Proxenetismo, modificado por el artículo $1^{\circ}$ de la Ley 28251:08-06-2004

Comprometer, seducir, o sustraer a una persona para entregarla a otro con el objeto de tener acceso carnal.

34 Artículo 179.- Favorecimiento a la prostitución, modificado por el artículo $1^{\circ}$ de la Ley 28251: 08-06-2004

Promover o favorecer la prostitución de otra persona.

35 Artículo 179-A.-Usuario-cliente, incorporado por el artículo $2^{\circ}$ de la Ley 28251:08-06-2004

Tener acceso carnal por vía vaginal, anal o bucal o realizar otros actos análogos introduciendo objetos o partes del cuerpo por alguna de las dos primeras vías con una persona de catorce y menor de dieciocho años, mediante una prestación económica o ventaja de cualquier naturaleza.

36 Artículo 181-A.- Explotación sexual comercial infantil y adolescente en ámbito del turismo, modificado por la segunda disposición final de la Ley 29408: 18 septiembre 2009

Promover, publicitar, favorecer o facilitar la explotación sexual comercial en el ámbito del turismo, a través de cualquier medio escrito, folleto, impreso, visual, audible, electrónico, magnético o a través de Internet, con el objeto de ofrecer relaciones sexuales de carácter comercial de personas de catorce (14) y menos de dieciocho (18) años de edad

37 Artículo 303-A.- Tráfico ilícito de migrantes, modificado por el artículo 2 de la Ley 28950, del 16 enero 2007

Promover, favorecer, financiar o facilitar la entrada o salida ilegal del país de otra persona, con el fin de obtener directa o indirectamente, lucro o cualquier otro beneficio para sí o para tercero.

38 PeÑa CABRERA Freyre, Alfonso Raúl. Derecho Penal. Parte Especial. T.II., EDEMSA., p.70. 


\subsection{Proxenetismo}

Delito en el cual, los agentes activos ${ }^{39}$ - hombres o mujeres - comprometen, seducen o sustraen a otra persona para mantener relaciones sexuales remuneradas con personas mayores o menores de edad.

\subsection{Favorecimiento a la prostitución}

Delito en el cual, las personas comprometidas degradan la vida sexual del sujeto pasivo a la realización de actividades sexuales que ponen en riesgo su normal desarrollo ${ }^{40}$.

\subsection{Delito usuario-cliente}

Delito en el cual, los sujetos activos ofrecen dinero por tener relaciones sexuales con un (a) adolescente. La aceptación del adolescente no elimina la responsabilidad atribuida.

\subsection{Delito de explotación sexual infantil y adolescente en ámbito del turismo}

Delito en el cual, los sujetos activos ${ }^{41}$ promueven, publican, favorecen o facilitan relaciones sexuales de carácter comercial de personas de catorce (14) y menos de dieciocho (18) años de edad, en el ámbito del turismo, aprovechando para esto escritos, folletos, impresos, imágines, correos electrónicos o el internet.

\subsection{Delito de tráfico ilícito de migrantes}

Delito en el cual, los sujetos activos promueven, favorecen, financian o facilitan la entrada o salida ilegal del país de una persona, con el fin de obtener directa o indirectamente, lucro o cualquier otro beneficio para sí o para tercero.

\section{Consideraciones finales}

El delito de "trata de personas" o "comercio de hombres", si se prefiere y que puede definirse pacíficamente, entonces, como un proceso de captación, transporte, traslado, acogida, recepción o retención de personas, recurriendo a la amenaza, al uso de la fuerza, a la coacción, al rapto, al engaño, al abuso de poder, a una situación de vulnerabilidad o a la concesión o recepción de

\footnotetext{
39 Proxenetas y/o promotores de la prostitución.

40 PeÑA CABRERAFREYRE, Alfonso Raúl. Obra cito., p. 22.

41 Pedófilos.
} 
pagos o beneficios para obtener el consentimiento de otro ser humano, específicamente mujeres, niños, niñas y adolescentes, con fines de explotación coactiva o fuerte, constituye, sin duda, una nueva forma de "esclavitud", un "delito transnacional" y un "crimen de lesa humanidad", que el Estado Peruano viene combatiendo aún, no obstante, sin la debida y más enérgica disposición.

El propósito, es que la "trata" no alcance mayores niveles de incidencia por el peligro que esto representa para todos.

La normativa positiva actual en nuestro país, siendo no obstante muy relevadora y expectante al tomar en expresa cuenta, sobre todo, el sustrato doctrinario establecido en la Convención de las Naciones Unidas contra la Delincuencia Organizada Transnacional (Protocolo de Palermo), prevé como puntos de acentuada connotación, de un lado, la absoluta carencia de efectos jurídicos que pudiera generar en la vida de relación el "consentimiento" otorgado por la víctima mayor de edad y a cualquier forma de explotación, razón por la cual, entonces, cuando el responsable del suceso recurriese al empleo de la violencia, de la amenaza, de la privación de libertad, del fraude, del engaño, del abuso de poder o de una situación de vulnerabilidad u otras formas de coacción, debe ser de plano investigado, procesado y sancionado ejemplarmente, incluso con pena privativa de libertad efectiva; de otra parte, una mejor amplitud y comprensión del tipo penal aplicable y, asimismo, el hecho de que la "trata" puede ser perpetrada no solo mediante autoría directa sino sobre todo mediante autoría mediata, en este caso por actitud de aquellos individuos que la promuevan, financien o faciliten.

El presente esfuerzo intelectual, que se ha consolidado gracias al generoso aporte de la señorita Paloma Andaluz Queirolo, pretende -como muchos otros- generar mayor conciencia en la ciudadanía y en las autoridades y, por supuesto, mejores decisiones institucionales de política criminal. 